\title{
COVID-19 in pregnancy
}

\author{
Authors: Melanie $\mathrm{Nana}^{\mathrm{A}}$ and Catherine Nelson-Piercy ${ }^{\mathrm{B}}$
}

Pregnant women with COVID-19 are less likely to be symptomatic than non-pregnant counterparts. Risk factors for severe disease include being overweight or obese, greater than 35 years old, and having pre-existing comorbidities. Those who develop severe disease have increased rates of admission to an intensive care unit, requiring invasive ventilation and pre-term birth.

Pregnant and breastfeeding women with COVID-19 should be investigated as of outside pregnancy and should receive proven therapies (such as corticosteroids and tocilizumab) on a risk/benefit basis. Admitted women should receive multidisciplinary care with input from senior decision makers and early escalation where required. There are no safety concerns surrounding the COVID-19 vaccination and fertility or pregnancy, and so it should be offered to women based on their age and clinical risk group, in line with non-pregnant women.

\section{Introduction}

In March 2020, the World Health Organization (WHO) declared a global pandemic of COVID-19 caused by SARS-CoV-2. As of July 2021 , there have been $>185$ million confirmed cases and $>4$ million deaths reported worldwide. ${ }^{1}$

Pregnant women have previously been at increased risk of severe maternal and neonatal morbidity and mortality from similar viral illnesses. As such, attention has focused on characterisation of this disease in pregnancy and its effects on maternal and neonatal outcomes. Here, we summarise the relevant literature and describe a suggested clinical management approach.

\section{Clinical manifestations and risk factors for severe disease}

Pregnant women with COVID-19 are less likely to be symptomatic than non-pregnant counterparts, with almost three-quarters being asymptomatic. ${ }^{2}$ For those who develop symptoms, they are usually mild, most commonly including cough (41\%), fever (40\%), dyspnoea $(21 \%)$ and myalgia $(19 \%)^{3}$

Authors: A clinical fellow in obstetric medicine, Guy's and St Thomas' NHS Foundation Trust, London, UK; ${ }^{\text {B }}$ consultant obstetric physician, Guy's and St Thomas' NHS Foundation Trust, London, UK and professor of obstetric medicine, King's Health Partners, London, UK
Severe disease during pregnancy is typically a phenomenon of the late second or third trimester. Risk factors reflect those in the non-pregnant population and include being overweight or obese, greater than 35 years old and having pre-existing comorbidities. ${ }^{4}$ In addition, women with COVID-19 from Black, Asian and minority ethnic (BAME) backgrounds have been demonstrated to be at increased risk both inside and outside of pregnancy, with health inequalities, socioeconomic factors and vitamin D deficiency proposed as contributing factors. ${ }^{5}$ The recent Mothers and Babies: Reducing Risk through Audits and Confidential Enquiries across the UK (MBRRACE-UK) report of the confidential enquiry into maternal death and morbidity, revealed an overall five times higher all-cause maternal mortality rate among women from Black compared with White ethnic groups. ${ }^{6}$ It is, therefore, paramount that healthcare professionals are aware of this increased risk of severe COVID-19 disease in the BAME population, and have a lower threshold to review, admit and consider multidisciplinary escalation in this group. ${ }^{5}$ In all pregnant women, we should discuss risk factors for severe disease and signs of deterioration, encouraging women to seek advice without delay if unwell.

\section{Key points}

COVID-19 disease in pregnancy is associated with increased rates of intensive care admission, invasive ventilation and pre-term birth.

Risk factors for severe disease include being overweight or obese, $>35$ years old, having pre-existing comorbidity and being Black, Asian and minority ethnic.

Proven therapies (such as corticosteroids and tocilizumab) should be offered to pregnant and breast-feeding women as in the non-pregnant population.

Women should receive multidisciplinary care with input from senior decision makers and early escalation where required.

Women planning pregnancy or those currently pregnant should not be denied the COVID-19 vaccination.

KEYWORDS: COVID-19, pregnancy, multidisciplinary care, vaccination, maternal outcomes

DOI: 10.7861/clinmed.2021-0503 


\section{Maternal, fetal and neonatal outcomes}

In total, $9 \%$ of all COVID-19 admissions to intensive care units (ICU) in the UK have comprised pregnant women or those within 6-weeks postpartum. ${ }^{7}$ The UK national cohort study performed using the UK Obstetric Surveillance System has reported 5\% of hospitalised pregnant women with COVID-19 have required ICU admission, with $<1 \%$ requiring extracorporeal membrane oxygenation. ${ }^{2}$ Compared with non-pregnant women of childbearing age with COVID-19, pregnant women are more likely to be admitted to an ICU (odds ratio (OR) 1.62; 95\% confidence interval (CI) 1.33-1.96) and are more likely to require invasive ventilation (OR 1.88; $95 \%$ CI 1.36-2.60). ${ }^{3}$ Of note, the proportion of women of childbearing age admitted to ICU with COVID-19 who were pregnant or within 6-weeks postpartum increased in the second wave, suggesting that this wave and the B.1.1.7 (alpha) variant had an increased detrimental effect on pregnant women when compared with the first. ${ }^{7}$ It should be considered, however, when interpreting these findings that the threshold for ICU admission tends to be lower in the pregnant population and that the overall maternal mortality rate is low (2.2 hospitalised women per 100,000 maternities). ${ }^{2}$

Pregnant women who are symptomatic with COVID-19 are at increased risk of pre-term birth compared with women without COVID-19 (<32 weeks' gestation (adjusted OR 3.98; 95\% CI 1.48-10.70); <37 weeks' gestation (adjusted OR 1.87; $95 \%$ CI $1.23-2.85))^{2}$ In almost $80 \%$ of cases, the preterm births are iatrogenic, undertaken to improve maternal oxygenation. Women with severe SARS-CoV-2 infection should, therefore, be managed in units with access to appropriate neonatal units.

\section{Investigations}

As with all medical problems in pregnancy, the priority should be confirming a diagnosis and stabilising the woman's condition with standard investigations and therapies considering a benefit/risk assessment. Pregnant women with suspected COVID-19 should not be denied imaging in the form of chest X-ray, ventilation/ perfusion scan or computed tomography pulmonary angiography, where indicated. Safety of relevant radiological investigations are summarised in Table $1 .{ }^{8}$ Differentials for the commonly presenting symptoms should be considered so that other important diagnoses are not overlooked. ${ }^{9}$

\section{Management}

Women with asymptomatic or mild disease may be managed at home with safety net advice and following venous thromboembolism risk assessment (Fig 1). Those with more severe disease should be admitted to hospital, isolated appropriately and have input from the multidisciplinary team (including consultant obstetrician, consultant physician / obstetric physician, consultant anaesthetist and midwives). Early escalation of deteriorating patients should also include involvement of a consultant intensivist and neonatologist. The Royal College of Obstetricians and Gynaecologists have published an example of a maternity escalation plan. ${ }^{5}$

An approach to clinical management is outlined in Fig 1. The Intensive Care National Audit \& Research Centre report demonstrated significant reductions in 28-day in-hospital mortality in the second wave; likely a tribute to the remarkable efforts invested by those developing evidence-based therapies over the previous year. ${ }^{7}$ Yet, in pregnant women in the UK, these therapies were only used in $<25 \%$ of women who would benefit from them including those who were critically ill. ${ }^{10}$ Pregnant women should not be denied these evidence-based therapies, the majority of which are acceptable on benefit/risk balance (safety profiles described in Table 2). If uncertainly exists, advice should be sought through maternal medicine networks. ${ }^{5}$

The RECOVERY trial demonstrated that low-dose dexamethasone reduced mortality by one-fifth in those receiving oxygen and by one-third in those requiring mechanical ventilation. ${ }^{11}$ Dexamethasone, however, readily passes the placenta, and repeated doses have been associated with neurocognitive and neurosensory disorders in childhood. ${ }^{12}$ As such, pregnant women in the trial received either oral prednisolone or intravenous hydrocortisone, both of which are extensively metabolised and have reduced transfer across the placenta (Fig 1). During pregnancy, dexamethasone should be reserved only for fetal lung maturity.

\section{Postnatal care}

There is robust evidence to support the benefits of early skin-toskin contact after birth and breastfeeding, including improved maternal-infant bonding and improved perinatal mental health outcomes. ${ }^{13}$ In a prospective UK population-based cohort study of babies with confirmed SARS-CoV-2 infection, the neonatal incidence of COVID-19 requiring inpatient care was reported as 5.6 per 10,000 live births. Infection with neonatal admission following birth to a mother with perinatal SARS-CoV-2 infection was unlikely, and possible vertical transmission was rare. ${ }^{13} \mathrm{WHO}$ therefore encourage keeping COVID-positive mothers and their babies together, encouraging breastfeeding using sensible hygiene

Table 1. Safety of commonly used radiological imaging for the management of COVID-19 in pregnancy ${ }^{8}$

\begin{tabular}{|c|c|c|}
\hline Imaging modality & Fetal radiation dose & Radiation to a mother's breasts \\
\hline & $\begin{array}{l}\text { (Threshold for fetal damage is } 50 \text { mGy, each } 1 \mathrm{mGy} \\
\text { increases the risk of fatal childhood cancer up to the } \\
\text { age of } 15 \text { years by } 0.006 \% \text { ) }\end{array}$ & $\begin{array}{l}\text { (10 mGy increases the lifetime risk of developing } \\
\text { breast cancer by } 13.6 \% \text {; modern protocols may lead } \\
\text { to reduced radiation) }\end{array}$ \\
\hline CXR & $0.0005-0.01 \mathrm{mGy}$ & $0.04 \mathrm{mGy}$ \\
\hline CTPA / CT of the thorax & $0.1 \mathrm{mGy}$ & 3-10 mGy \\
\hline $\mathrm{V} / \mathrm{Q}$ & $0.32-0.74 \mathrm{mGy}$ & $0.22-0.28$ mGy \\
\hline US Doppler & $\mathrm{n} / \mathrm{a}$ & $\mathrm{n} / \mathrm{a}$ \\
\hline
\end{tabular}



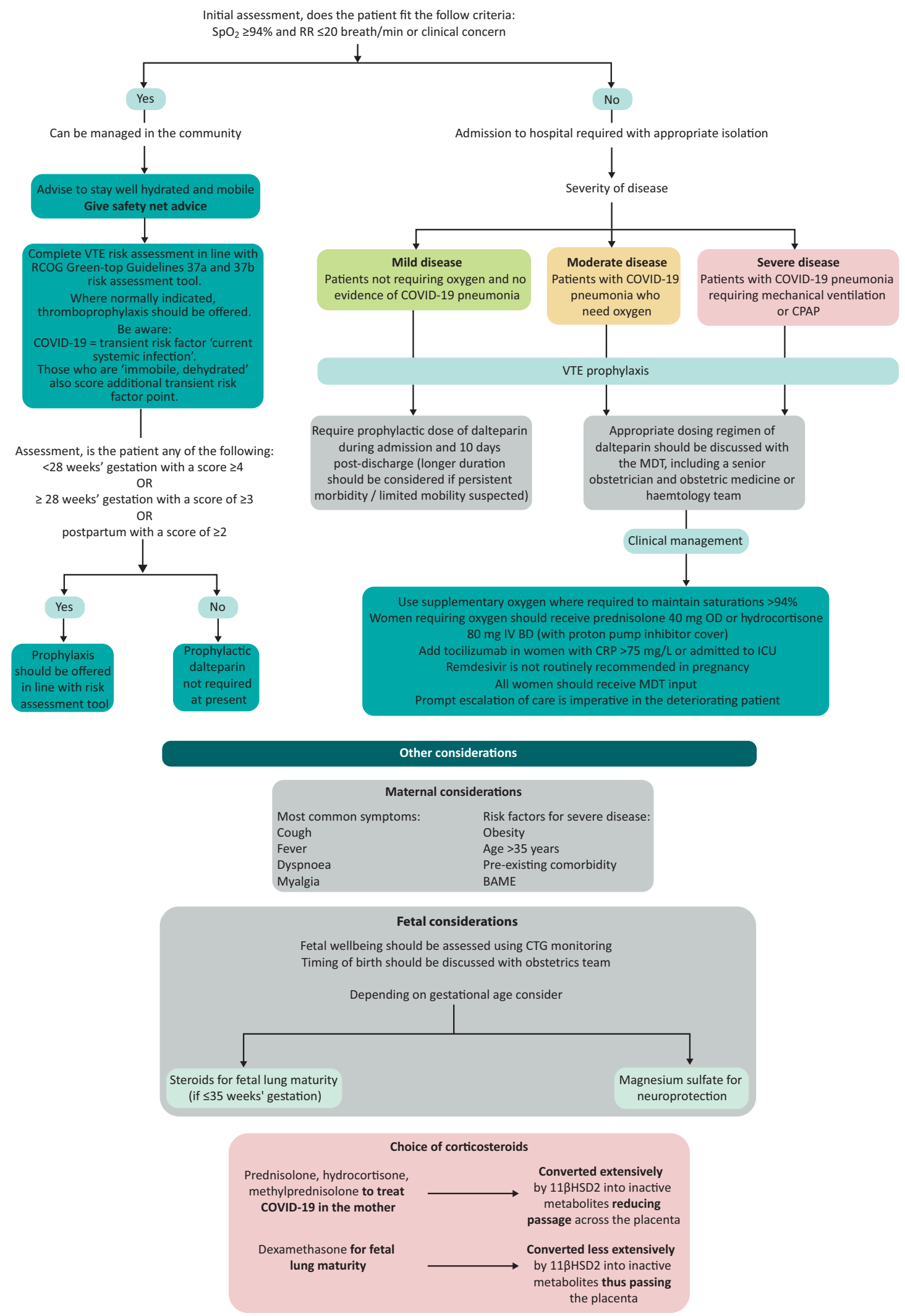

Fig 1. Management of women with COVID-19 who are pregnant or up to 6 weeks postpartum. BAME = Black, Asian and minority ethnic; BD = twice a day; $C R P$ = C-reactive protein; $C T G$ = cardiotocography; ICU = intensive care unit; IV = intravenous; $L M W H=$ low-molecular weight heparin; MDT = multidisciplinary team; $\mathrm{OD}=$ once a day; $\mathrm{RCOG}=$ Royal College of Obstetricians and Gynaecologists; $\mathrm{RR}=$ respiratory rate; $\mathrm{SpO}_{2}=$ oxygen saturation; VTE $=$ venous thromboembolism. 
Table 2. Safety of commonly used treatments for the management of COVID-19 in pregnancy ${ }^{8}$

\begin{tabular}{|c|c|}
\hline Treatment & Use in pregnancy \\
\hline Oxygen & Should be used to maintain saturations $>94 \%$ \\
\hline Prednisolone & $\begin{array}{l}\text { Demonstrated to reduce } 28 \text {-day mortality among those requiring invasive mechanical ventilation or oxygen alone: } \\
\text { Indicated in women who are receiving supplementary oxygen } \\
\text { Dose: prednisolone } 40 \mathrm{mg} \text { OD PO or hydrocortisone } 80 \mathrm{mg} \text { IV BD } \\
\text { Monitoring: Capillary blood glucose monitoring after meals } \\
\text { Omit if fetal steroids given that day } \\
\text { Best quality evidence does not suggest increased malformation rates, increased risk of miscarriage, intrauterine } \\
\text { death or fetal growth restriction } \\
\text { A small number of studies have demonstrated increased risk of preterm birth (likely confounded by an underlying } \\
\text { condition) }\end{array}$ \\
\hline Tocilizumab & $\begin{array}{l}\text { Demonstrated to improve survival and reduce the chance of progression to invasive mechanical ventilation in } \\
\text { patients admitted to hospital with COVID- } 19 \text { with hypoxia and systemic inflammation (RECOVERY): } \\
\text { Indicated in women with CRP }>75 \mathrm{mg} / \mathrm{L} \text { or admission to ICU } \\
\text { Dose: } 800 \mathrm{mg} \text { if }>90 \mathrm{~kg} ; 600 \mathrm{mg} \text { if }>65 \mathrm{~kg} \text { and } \leq 90 \mathrm{~kg} ; 400 \mathrm{mg} \text { if }>40 \mathrm{~kg} \text { and } \leq 65 \mathrm{~kg} ; 8 \mathrm{mg} / \mathrm{kg} \text { if weight } \leq 40 \mathrm{~kg} \\
\text { Rates of congenital abnormality, spontaneous pregnancy loss ( } 22 \% \text { ) and other adverse outcomes were no higher } \\
\text { than in general population } \\
\text { Malformation rate reported as } 4.5 \% \text { (background } 3 \% \text { ) but } 20 \% \text { of patients co-medicated with methotrexate } \\
\text { If used after } 20 \text { weeks' gestation, avoid live vaccines (BCG or rotavirus) until the baby is } 6 \text { months old, as some } \\
\text { evidence of transplacental transfer }\end{array}$ \\
\hline Remdesivir & $\begin{array}{l}\text { Demonstrated to reduce time taken until clinical improvement in those with severe COVID-19 from a median of } \\
15 \text { to } 11 \text { days (ACTT-1 study), however, the SOLIDARITY trial showed no reduction in mortality rates, the need for } \\
\text { invasive ventilation or duration of hospital stay: } \\
\text { Not routinely recommended in pregnancy } \\
\text { Very limited animal or human pregnancy exposure data are available }\end{array}$ \\
\hline \multicolumn{2}{|c|}{ VTE prophylaxis } \\
\hline \multicolumn{2}{|c|}{$\begin{array}{l}\text { All pregnant women admitted with SARS-CoV-2 infection (or suspected SARS-CoV- } 2 \text { infection) should receive prophylactic LMWH, unless } \\
\text { birth is expected within } 12 \text { hours (eg for a woman with increasing oxygen requirements) } \\
\text { All women admitted to hospital with SARS-CoV- } 2 \text { infection should receive at least } 10 \text { days of prophylactic LMWH following discharge } \\
\text { from hospital }\end{array}$} \\
\hline
\end{tabular}

precautions. ${ }^{13}$ Physicians should act as advocates for mothers by ensuring the baby stays with the mother or that contact time is facilitated if in the ICU setting.

Women who have been critically unwell with possible periods of separation from their newborn should be supported in a holistic fashion with input, if necessary, from the perinatal mental health team. In addition, the psychological effects on women's partners should also be considered. ${ }^{14}$

\section{COVID-19 vaccination in pregnancy}

The Joint Committee on Vaccination and Immunisation endorse the vaccination of pregnant women, based on their age and clinical risk group, in line with non-pregnant women. There is no biologically plausible mechanism by which any of the vaccines should cause harm either in the periconception period, throughout gestation or during breastfeeding. Women should have the opportunity to discuss any concerns with a healthcare professional so that they can make an informed decision. ${ }^{5}$

As of June 2021 , over 120,000 pregnant women in the USA have received a COVID-19 vaccination with no concerns identified. ${ }^{15}$ The outcomes of 3,958 women vaccinated with the PfizerBioNTech or Moderna vaccines in the periconception period or during pregnancy have been reported. ${ }^{16}$ At the time of reporting, there were 827 completed pregnancies, of which, 712 resulted in live births (700 of which the women were vaccinated in the first trimester). Adverse outcomes (including spontaneous miscarriage, stillbirth, preterm birth and small size for gestational age) were comparable to the background population. There were no neonatal deaths reported and, among those babies with reported congenital anomalies, none had received the vaccine in the periconception period / first trimester.

Where possible, either the Pfizer-BioNTech or Moderna vaccine should be offered in pregnancy as they currently have the greatest wealth of safety data available, unless the woman has already received a first dose of the AstraZeneca vaccine (in which case she should complete the course). Growing evidence supports passage of vaccine-elicited antibodies into the infant cord blood and breastmilk conferring benefit to the neonate. ${ }^{17}$

\section{Conclusion}

The large majority of women who contract COVID-19 during pregnancy will be asymptomatic or suffer only mild disease. The risks in the small subset of women who develop more severe disease, however, are not insignificant with increased rates of ICU 
admission, invasive ventilation and preterm birth when compared with the non-pregnant population. Proven therapies (such as corticosteroids and tocilizumab) should be offered to pregnant and breast-feeding women as in the non-pregnant population. Admitted women should receive multidisciplinary care with input from senior decision makers and early escalation where required. Women planning pregnancy or those currently pregnant should not be denied the COVID-19 vaccination.

We, as physicians should enable ourselves to advocate for prompt and appropriate care for such women by equipping ourselves with the necessary knowledge and being prepared to liaise with the wider multidisciplinary team and maternal medicine networks when required.

\section{Conflicts of interest}

Catherine Nelson-Piercy has received consultancy fees from UC and Sanofi and speaker fees from UC, Sanofi, Alexion Pharmaceuticals and Janssen Pharmaceuticals.

\section{References}

1 World Health Organization. WHO Coronavirus (COVID-19) Dashboard. WHO, 2021. https://covid19.who.int [Accessed 11 July 2021].

2 Vousden N, Bunch K, Morris E et al. The incidence, characteristics and outcomes of pregnant women hospitalized with symptomatic and asymptomatic SARS-CoV-2 infection in the UK from March to September 2020: A national cohort study using the UK Obstetric Surveillance System (UKOSS). PLoS One 2021;16:e0251123.

3 Allotey J, Stallings E, Bonet M et al. Clinical manifestations, risk factors, and maternal and perinatal outcomes of coronavirus disease 2019 in pregnancy: living systematic review and metaanalysis. BMJ 2020;370:m3320.

4 Knight M, Bunch K, Vousden N et al. Characteristics and outcomes of pregnant women admitted to hospital with confirmed SARS-CoV-2 infection in UK: national population based cohort study. BMJ 2020;369:m2107.

5 Royal College of Obstetricians and Gynaecologists. Coronavirus (COVID-19) Infection in Pregnancy. RCOG, 2021. www.rcog.org.uk/ globalassets/documents/guidelines/2021-02-19-coronavirus-covid19-infection-in-pregnancy-v13.pdf [Accessed 11 July 2021].

6 Knight M, Bunch K, Tuffnell D et al. Saving lives, improving mothers' care. MBRRACE-UK, 2020. www.npeu.ox.ac.uk/ assets/downloads/mbrrace-uk/reports/maternal-report-2020/ MBRRACE-UK_Maternal_Report_Dec_2020_v10_ONLINE_ VERSION_1404.pdf [Accessed 11 July 2021].
7 Intensive Care National Audit \& Research Centre. ICNARC report on COVID-19 in critcal care: England, Wales and Northern Ireland. ICNARC, 2021. www.icnarc.org/Our-Audit/Audits/Cmp/Reports [Accessed 11 July 2021].

8 Burton KR, Park AL, Fralick M, Ray JG. Risk of early-onset breast cancer among women exposed to thoracic computed tomography in pregnancy or early postpartum. J Thromb Haemost 2018;16:876-85.

9 Royal College of Physicians. Acute care toolkit 15: Managing acute medical problems in pregnancy. RCP, 2019. www.rcplondon.ac.uk/ guidelines-policy/acute-care-toolkit-15-managing-acute-medicalproblems-pregnancy [Accessed 11 July 2021].

10 Scientific Advisory Group for Emergencies. UKOSS/ISARIC/CO-CIN: Females in Hospital with SARS-CoV-2 infection, the association with pregnancy and pregnancy outcomes, 25 March 2021. Scientific Advisory Group for Emergencies, 2021. www.gov.uk/ government/publications/ukossisaricco-cin-females-in-hospitalwith-sars-cov-2-infection-the-association-with-pregnancy-andpregnancy-outcomes-25-march-2021 [Accessed 11 July 2021].

11 Nuffield Department of Population Health. RECOVERY: Randomised Evaluation of COVID-19 Therapy. University of Oxford, 2020. www.recoverytrial.net [Accessed 9 July 2021].

12 Magala Ssekandi A, Sserwanja Q, Olal E et al. Corticosteroids use in pregnant women with COVID-19: recommendations from available evidence. J Multidiscip Healthc 2021;14:659-63.

13 Gale C, Quigley MA, Placzek A et al. Characteristics and outcomes of neonatal SARS-CoV-2 infection in the UK: a prospective national cohort study using active surveillance. Lancet Child Adolesc Health 2021:5:113-21.

14 Vasilevski V, Sweet L, Bradfield Z et al. Receiving maternity care during the COVID-19 pandemic: Experiences of women's partners and support persons. Women Birth 2021 [Epub ahead of print].

15 Centers for Disease Control and Prevention. V-safe COVID-19 Vaccine Pregnancy Registry. CDC, 2021 www.cdc.gov/ coronavirus/2019-ncov/vaccines/safety/vsafepregnancyregistry. html [Accessed 6 June 2021].

16 Shimabukuro TT, Kim SY, Myers TR et al. Preliminary findings of mRNA Covid-19 vaccine safety in pregnant persons. N Engl ] Med 2021;384:2273-82.

17 Collier AY, McMahan K, Yu J et al. Immunogenicity of COVID-19 mRNA vaccines in pregnant and lactating women. JAMA 2021;325:2370-80.

Address for correspondence: Dr Melanie Nana, St Thomas' Hospital, Westminster Bridge Road, London SE1 7EH, UK. Email: melanienana28@hotmail.com Twitter: @Melanie_Nana1; @nelson_piercy 